\title{
Epoxy resin coatings modified by ionic liquid. Study of abrasion resistance
}

\author{
M. D. Avilés, N. Saurín, F. J. Carrión, J. Arias-Pardilla, I. Martínez-Mateo, J. Sanes, \\ M. D. Bermúdez*
}

Grupo de Ciencia de Materiales e Ingeniería Metalúrgica, Universidad Politécnica de Cartagena. Campus de la Muralla del Mar. 30202 Cartagena, Spain

Received 26 September 2018; accepted in revised form 7 November 2018

\begin{abstract}
In the present study, an epoxy resin coating containing a uniformly dispersed $9 \mathrm{wt} \%$ of the ionic liquid 1-octyl3-methylimidazolium tetrafluoroborate $\left(\mathrm{EP}+9 \%[\mathrm{OMIM}] \mathrm{BF}_{4}\right)$ has been applied by spin coating on a neat epoxy substrate, and its abrasion resistance under multiple scratch has been compared with that of neat epoxy coating. EP+9\%[OMIM] $\mathrm{BF} 4$ presents the lowest surface damage after 15 successive scratches. The ionic liquid-modified coating reduces instantaneous penetration depth in a $13 \%$ and residual depth in a $22 \%$ with respect to EP, and increases viscoelastic recovery (after 30 seconds) in a $7.6 \%$. The lubricating effect of the ionic liquid reduces the coefficient of friction up to the tenth scratch number. $\mathrm{EP}$ and $\mathrm{EP}+9 \%[\mathrm{OMIM}] \mathrm{BF}_{4}$ have also been obtained in the form of spin-coated films with similar visual transparency. Dynamic-mechanical characterization of the films under a tensile configuration confirms that the addition of the ionic liquid increases the ductility and reduces the glass transition temperature of the epoxy resin.
\end{abstract}

Keywords: coatings, films, epoxy resin, ionic liquid, abrasion

\section{Introduction}

As in many other scientific and technological fields, it can be said that ionic liquids (ILs) are making a deep impact in the development of new thermoset polymers, with special emphasis on epoxy resin materials $[1,2]$. Epoxy resins modified by the addition of ILs are the object of wide interest for their improved properties and potential applications. Roomtemperature ionic liquids play multiple roles when used as additives of epoxy thermosets [3], ranging from catalysts and curing agents [4] to plasticizers or precursors of conducting [5-7] and more sustainable materials [8].

Very recent studies are focusing on the effect of different fillers on the tribological performance of epoxybased bulk materials, coatings and films [9-14]. From the point of view of improving the poor tribological performance or epoxy resin, ILs have shown their ability to reduce the brittleness of the bulk epoxy matrix materials, reducing friction coefficients and protecting against wear [15-20].

The first dispersion of a room temperature IL in an epoxy resin matrix with the purpose of improving its tribological performance was that of the short alkyl chain 1-ethyl-3-methylimidazolium tetrafluoroborate [20], which is not miscible with the epoxy network but distributes into microcavities. A higher compatibility with the epoxy matrix was achieved by increasing the length of the alkyl chain from two to eight carbon atoms, using 1-octyl-3-methylimidazolium tetrafluoroborate ([OMIM] $\mathrm{BF}_{4}$ ) [15-18]. In the case of bulk epoxy resin containing $[\mathrm{OMIM}] \mathrm{BF}_{4}$, the IL increases the immediate surface damage by scratch due to the reduction in hardness and glass 
transition temperature, and to the increase in ductility [21]. However, the IL induces a self-healing of the abrasion damage plastic deformation up to $96 \%$ after 22 hours [15] for a $9 \mathrm{wt} \%$ [OMIM] $\mathrm{BF}_{4}$. In the present study, we have used the spin coating technique $[22,23]$ to obtain epoxy resin coatings and films containing $9 \mathrm{wt} \%[\mathrm{OMIM}] \mathrm{BF}_{4}$.

The need for new epoxy coatings with improved abrasion resistance and lower friction coefficients is a very active field at the present moment [24]. Very recent results have shown the feasibility of the spin coating method for applying epoxy resin nanocomposites containing protic or aprotic ionic liquids and dispersions of graphene in ionic liquids as protective coatings, for the friction and wear [25] reduction of mild steel substrates [26].

The aim of the present work is to use epoxy resin substrates to develop new gradient composition materials, where the additive is concentrated exclusively where it is needed, that is, at the surface layer, without modifying the bulk epoxy substrate. Neat epoxy resin (EP) and $\mathrm{EP}+9 \%[\mathrm{OMIM}] \mathrm{BF}_{4}$ have been also obtained in the form of spin-coated films in order to determine the effect of the additive on the properties of the epoxy resin.

\section{Experimental}

\subsection{Materials}

The ionic liquid additive used is 1-octyl-3-methylimidazolium tetrafluoroborate [OMIM] $\mathrm{BF}_{4}(>98 \% \mathrm{pu}-$ rity; Fluka, Germany) (Figure 1). Neat epoxy resin (EP) substrates $(25 \times 25 \times 10 \mathrm{~mm})$ were obtained by adding $28 \mathrm{wt} \%$ of the hardener composed by a mixture of amines $[16,20]$ to bisphenol A epichlorhydrin, and stirring for 3 minutes at room temperature, as previously described [20]. EP coating was obtained by deposition of the same mixture of prepolymer and hardener on a previously cured neat epoxy resin substrate by spin coating (Spin Coater 150i infinite de POLOS TM, SPS-Europe B.V. The Netherlands), at $2500 \mathrm{rpm} / \mathrm{s}$, for 60 seconds. EP+9wt\%[OMIM] $\mathrm{BF}_{4}$ surface layer was obtained by adding the corresponding IL proportion to the prepolymer and stirring for 3 minutes, before adding the hardener, and spin-coating the mixture on the neat epoxy substrate. Coated

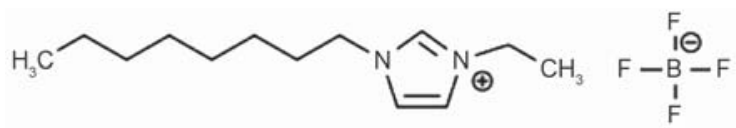

Figure 1. Ionic liquid 1-octyl-3-methylimidazolium tetrafluoroborate. samples were then cured at $60^{\circ} \mathrm{C}$ for 2 hours, and postcured at room temperature for 24 hours.

Films of EP and $\mathrm{EP}+9 \mathrm{wt} \%[\mathrm{OMIM}] \mathrm{BF}_{4}$ were spincoated on polystyrene (PS) discs, with a diameter of $40 \mathrm{~mm}$ and an average surface roughness $\left(R_{\mathrm{a}}\right)$ of $0.17 \pm 0.018 \mu \mathrm{m}$, under the same conditions used for the coatings deposited on epoxy substrates. The films were cured following the same procedure described above for the coatings. Cured films were then removed from PS substrates and their thickness was measured with a micrometer.

\subsection{Multiple scratch test}

Multiple scratch abrasion tests $\left(25^{\circ} \mathrm{C} ; 50 \% \mathrm{HR}\right)$ were performed on the coatings with a MTR 3/5050/NI Microtest Scratch tester with a diamond tip indenter $\left(200 \mu \mathrm{m}\right.$ diameter and $120^{\circ}$ cone angle) following the previously described experimental procedure [15]. Each of the 15 successive scratches was performed under the conditions described in Table 1. Friction coefficient, instantaneous penetration depth $(P d)$ and residual depth $(R d)$ values were determined as a function of scratch number. Viscoelastic recovery was calculated from $P d$ and $R d$ values as: $\% R=$ $[(P d-R d) / P d] \cdot 100$. Final values (Tables 2,3 and Figure 3$)$ are the average of three tests under the same conditions, with standard deviations lower than $5 \%$.

\subsection{Characterization techniques}

Optical micrographs were obtained with a Leica DMR optical microscope, and SEM micrographs with a Hitachi S-3500N. Surface topography and roughness values $\left(R_{\mathrm{a}}\right)$ were determined with a Talysurf CLI 500 (Taylor Hobson) optical profiler. Dynamic mechanical analysis (DMA) of the films was performed with a DMA Q800 (TA Instruments) under tensile configuration, from 25 to $120^{\circ} \mathrm{C}$, at a heating rate of $3{ }^{\circ} \mathrm{C} \cdot \mathrm{min}^{-1}$. Results are the average values after three tests.

\section{Results and discussion}

\subsection{Coatings}

Cross sections of the coated epoxy resin samples are shown in Figures 2a and 2b. The thickness of the ILcontaining coating is lower than that of IL-free EP coating. Surface roughness $\left(R_{\mathrm{a}}\right)$ of EP $+9 \%[\mathrm{OMIM}] \mathrm{BF}_{4}$ coating $(0.11 \mu \mathrm{m})$ is also lower than that of the EP coating $(0.18 \mu \mathrm{m})$. 


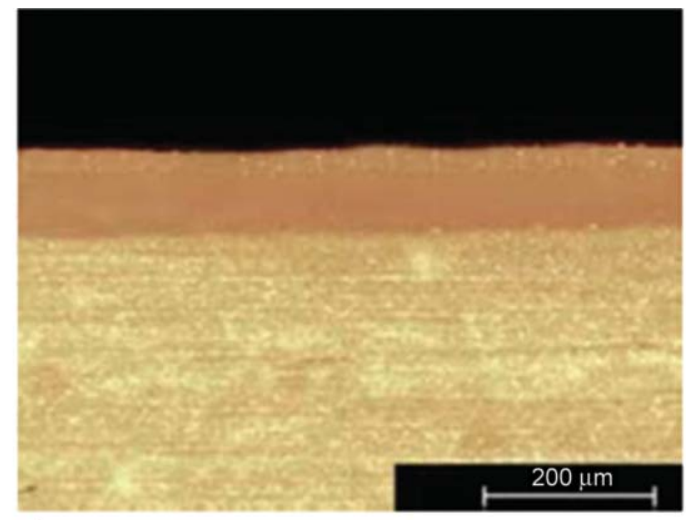

a)

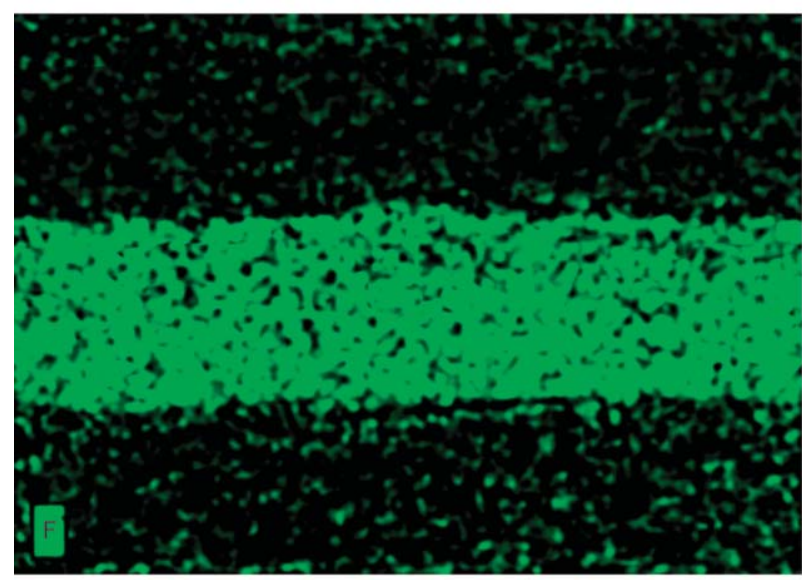

c)

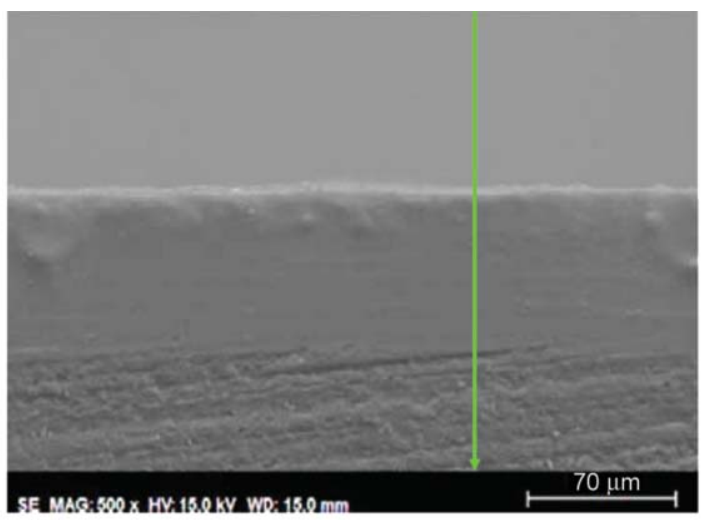

b)

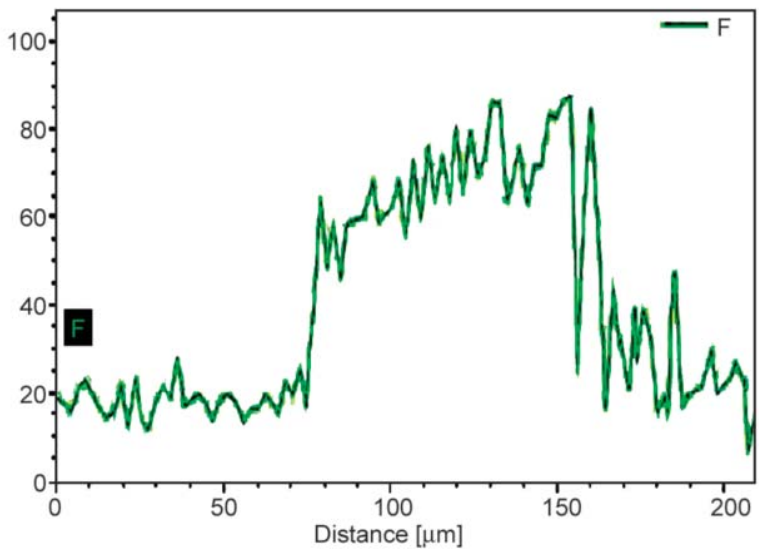

d)

Figure 2. a) Optical micrograph of the cross section of EP on epoxy resin substrate; b) SEM micrograph of EP+9\%[OMIM]BF 4 on epoxy resin substrate; c) Fluorine EDX element map for EP+9\%[OMIM]BF 4 on epoxy resin substrate; d) EDX fluorine line analysis along the line shown in b).

The concentration and distribution of the IL within the $\mathrm{EP}+9 \%[\mathrm{OMIM}] \mathrm{BF}_{4}$ coating layer has been determined by the fluorine EDX element map (Figure 2c) and the fluorine analysis (Figure 2d) along the line shown in Figure $2 b$. The results show that the spin coating method has been adequate for the preparation of a homogeneous dispersion of the IL, which is concentrated at the surface layer.

Abrasion resistance results under the experimental conditions summarized in Table 1, are presented as a function of scratch number in Tables 2 and 3 and in Figures 3.

Although under the first single scratch, the instantaneous abrasion resistance of the IL-modified coating

Table 1. Multiple scratch test conditions.

\begin{tabular}{|ll|c|}
\hline Normal applied load & {$[\mathrm{N}]$} & 5 \\
\hline Number of scratches & & 15 \\
\hline Length & {$[\mathrm{mm}]$} & 5 \\
\hline Velocity & {$\left[\mathrm{m} \cdot \mathrm{min}^{-1}\right]$} & 5 \\
\hline Temperature & {$\left[{ }^{\circ} \mathrm{C}\right]$} & 25 \\
\hline Relative humidity & {$[\%]$} & 50 \\
\hline
\end{tabular}

is lower than that of EP coating, as a result of the softening effect of the fluid phase, its performance improves with the increase of successive slidings.

Table 2. Results of multiple scratch tests for EP coating.

\begin{tabular}{|c|c|c|c|c|}
\hline $\begin{array}{c}\text { Scratch } \\
\text { number }\end{array}$ & $\begin{array}{c}\boldsymbol{P d} \\
{[\boldsymbol{\mu m}]}\end{array}$ & $\begin{array}{c}\boldsymbol{R} \boldsymbol{d} \\
{[\boldsymbol{\mu m}]}\end{array}$ & $\begin{array}{c}\text { Viscoelastic recovery } \\
{[\%]}\end{array}$ & $\begin{array}{c}\text { Coefficient } \\
\text { of friction }\end{array}$ \\
\hline 1 & 40.1 & 16.6 & 60.9 & 0.22 \\
\hline 2 & 42.2 & 20.4 & 56.2 & 0.30 \\
\hline 3 & 46.8 & 23.5 & 53.8 & 0.30 \\
\hline 4 & 51.5 & 25.2 & 52.2 & 0.26 \\
\hline 5 & 53.9 & 28.2 & 53.6 & 0.25 \\
\hline 6 & 54.3 & 29.7 & 48.9 & 0.26 \\
\hline 7 & 56.8 & 29.8 & 50.9 & 0.21 \\
\hline 8 & 57.3 & 30.1 & 50.2 & 0.22 \\
\hline 9 & 58.1 & 30.4 & 50.3 & 0.21 \\
\hline 10 & 58.1 & 30.3 & 50.6 & 0.21 \\
\hline 11 & 58.5 & 30.8 & 49.9 & 0.21 \\
\hline 12 & 58.5 & 31.0 & 49.7 & 0.20 \\
\hline 13 & 58.8 & 31.1 & 50.1 & 0.21 \\
\hline 14 & 59.1 & 31.3 & 49.8 & 0.21 \\
\hline 15 & 59.4 & 31.5 & 49.7 & 0.21 \\
\hline
\end{tabular}


Friction coefficient values (Figure 3a), measured simultaneously to abrasion resistance, show that the lubricating ability of the ionic liquid fluid additive [16] reduces friction values, with respect to neat

Table 3. Results of multiple scratch tests for $\mathrm{EP}+9 \%[\mathrm{OMIM}] \mathrm{BF}_{4}$ coating.

\begin{tabular}{|c|c|c|c|c|}
\hline $\begin{array}{c}\text { Scratch } \\
\text { number }\end{array}$ & $\begin{array}{c}\boldsymbol{P d} \\
{[\boldsymbol{\mu} \mathbf{m}]}\end{array}$ & $\begin{array}{c}\boldsymbol{R d} \\
{[\boldsymbol{\mu} \mathbf{m}]}\end{array}$ & $\begin{array}{c}\text { Viscoelastic recovery } \\
{[\mathbf{\%}]}\end{array}$ & $\begin{array}{c}\text { Coefficient } \\
\text { of friction }\end{array}$ \\
\hline 1 & 25.5 & 8.9 & 63.4 & 0.41 \\
\hline 2 & 42.4 & 17.9 & 58.2 & 0.22 \\
\hline 3 & 44.1 & 19.5 & 56.1 & 0.23 \\
\hline 4 & 45.3 & 20.6 & 54.8 & 0.22 \\
\hline 5 & 46.1 & 21.4 & 53.9 & 0.21 \\
\hline 6 & 46.7 & 21.9 & 53.2 & 0.21 \\
\hline 7 & 47.2 & 22.3 & 53.0 & 0.21 \\
\hline 8 & 47.6 & 22.8 & 52.4 & 0.21 \\
\hline 9 & 47.9 & 22.4 & 53.3 & 0.21 \\
\hline 10 & 47.4 & 22.6 & 52.6 & 0.21 \\
\hline 11 & 47.8 & 22.7 & 52.7 & 0.21 \\
\hline 12 & 48.0 & 23.2 & 52.0 & 0.20 \\
\hline 13 & 48.3 & 23.4 & 52.0 & 0.21 \\
\hline 14 & 48.5 & 23.5 & 51.8 & 0.20 \\
\hline 15 & 48.6 & 23.8 & 51.4 & 0.20 \\
\hline
\end{tabular}

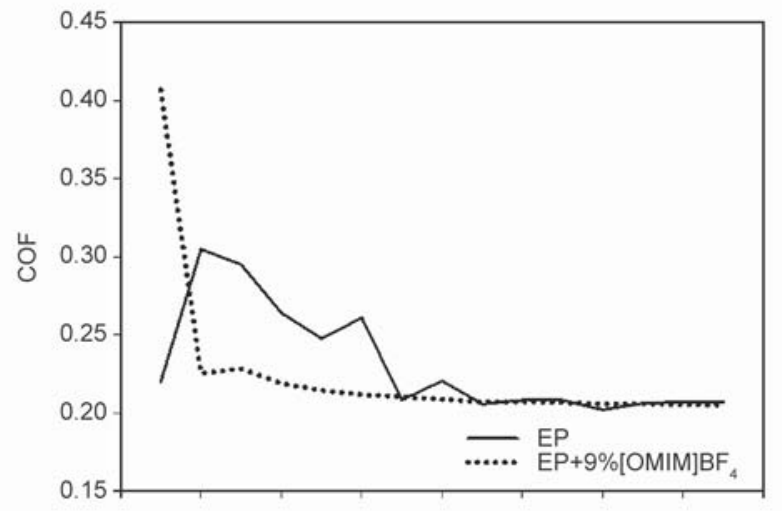

a)

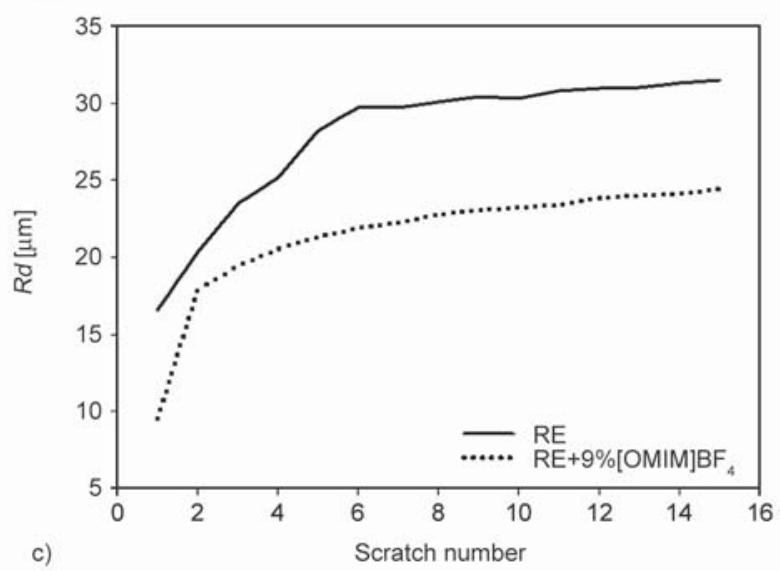

epoxy, from 2 to 7 scratches. However, final friction values as surface damage is more severe, from 7 to 15 scratch numbers, are very similar to those found for the unmodified EP coating.

Figure $3 \mathrm{~b}$ shows the evolution of instantaneous penetration depth. After a sharp penetration depth increase from the first to the second sliding, the coating containing the ionic liquid reaches an asymptotic behaviour. In contrast, EP coating needs 7 scratches to reach the asymptote (Figure $3 b$ ).

As described by Brostow et al. [27], polymers under multiple scratch tests reach asymptotic penetration values after a critical number of slidings on the same path, in a strain-hardening effect. In the present case, neat epoxy requires at least 7-9 slidings to reach such behaviour, while the results for $\mathrm{EP}+9 \%[\mathrm{OMIM}] \mathrm{BF}_{4}$ stabilize after just 3 scratches (Tables 2, 3; Figure 3b). This is attributed to the EP brittleness reduction [28] by the addition of IL. A final $13 \%$ reduction of the instantaneous penetration $(P d)$ with respect to EP is found after 15 scratches.

Residual depth $(R d)$ values (Figure 3c), which represent permanent surface damage after viscoelastic
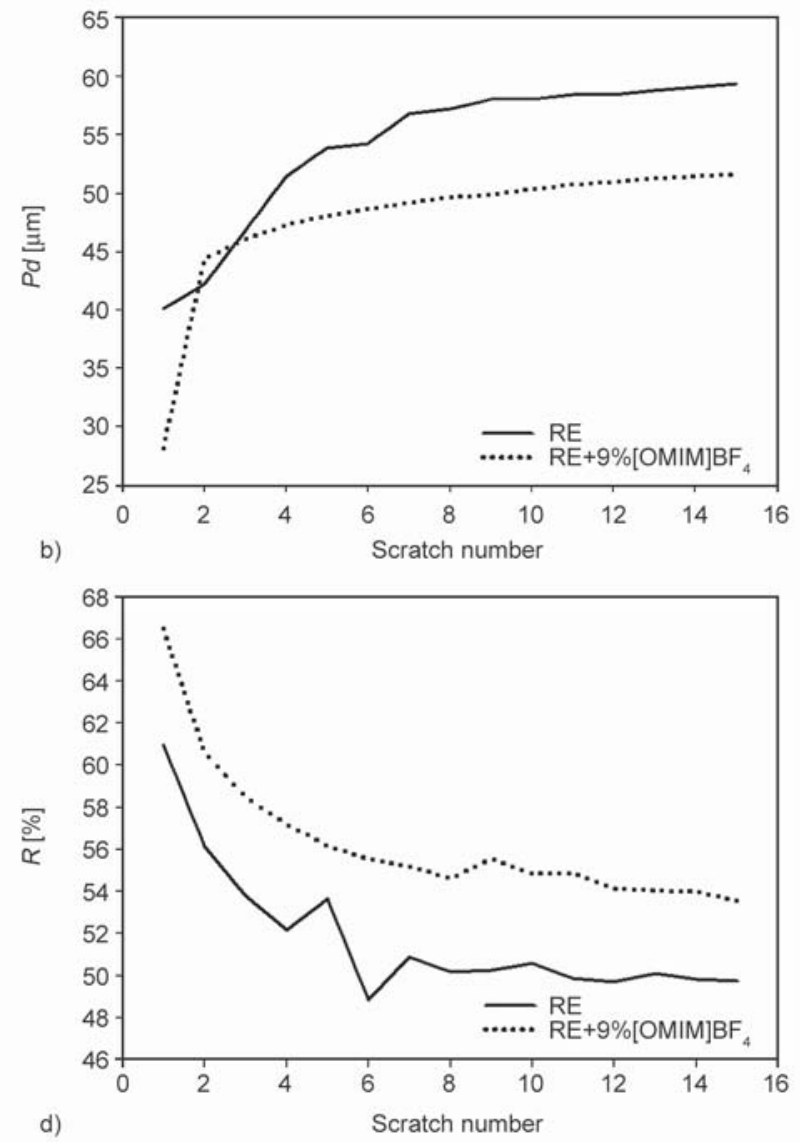

Figure 3. a) Friction coefficient $(\mathrm{COF})$; b) penetration depth $(P d)$ for $\mathrm{EP}$ and $\mathrm{EP}+9 \%[\mathrm{OMIM}] \mathrm{BF}_{4}$; c) residual depth $(R d)$ and $\mathrm{d})$ viscoelastic recovery $(R[\%])$ for $\mathrm{EP}$ and $\mathrm{EP}+9 \%[\mathrm{OMIM}] \mathrm{BF}_{4}$ as a function of scratch number. 
recovery, are recorded 30 seconds after each sliding, and are shown in Figure 3c. Again, the highest abrasion resistance after 15 scratches is found for the coating that contains ionic liquid, $\mathrm{EP}+[\mathrm{OMIM}] \mathrm{BF}_{4}$, with a $22 \%$ reduction with respect to EP coating. The best performance of the coating with the ionic liquid fluid phase can be attributed to its ability to present a higher viscoelastic recovery, as shown in Tables 2 and 3 , and in Figure 3d. The final increase in viscoelastic recovery after 15 scratches is $7.6 \%$, with the addition of the IL.

Figure 4 shows the profilometry images of the final abrasion scars after 15 scratches. Neat EP coating (Figure 4a) has suffered severe surface damage, with removal of wear debris outside the wear track. In contrast, $\mathrm{EP}+9 \%[\mathrm{OMIM}] \mathrm{BF}_{4}$ coating (Figure $4 \mathrm{~b}$ ) shows plastic deformation without removal of wear debris, and with accumulation of the material pushed by the indenter tip at the end of the abrasion groove.

The results described above for the new coatings are in contrast with those previously described for the scratch resistance of the bulk materials obtained by conventional casting techniques. In the case of bulk $\mathrm{EP}+9 \%[\mathrm{OMIM}] \mathrm{BF}_{4}$, the addition of $9 \mathrm{wt} \%$ IL decreases abrasion resistance with respect to neat epoxy resin. However, the bulk-modified $\mathrm{EP}+9 \%[\mathrm{OMIM}] \mathrm{BF}_{4}$ is able to self-heal the surface damage produced by abrasion after a period of 22 hours [15].

The different behaviour of $\mathrm{EP}+9 \%[\mathrm{OMIM}] \mathrm{BF}_{4}$ coating with respect to the bulk material is attributed to the different processing techniques. As it has been described [23], the spin coating method changes the properties of the deposited epoxy layers. In this case,

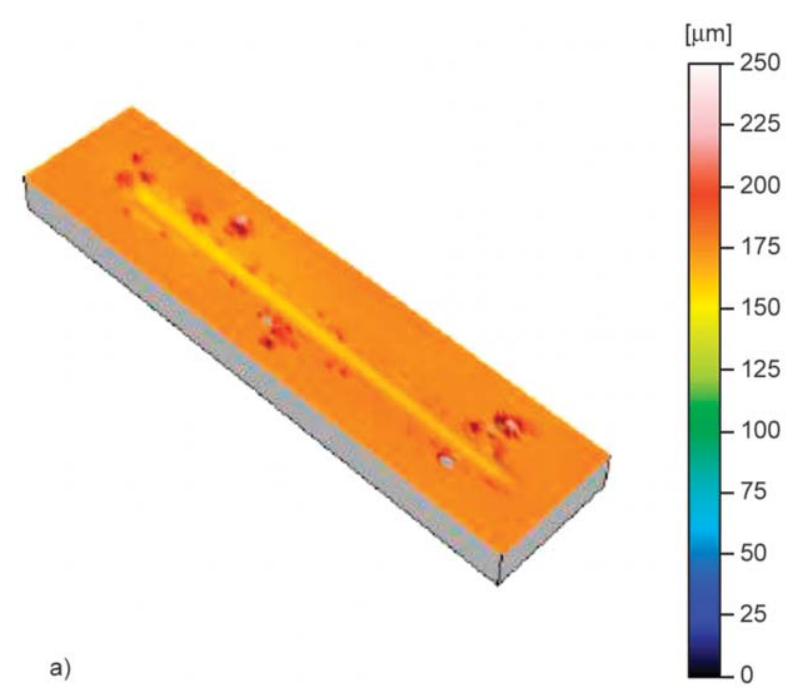

the abrasion resistance found for spin-coated neat epoxy resin is lower than that of the bulk cast material. The best performance of $\mathrm{EP}+9 \%[\mathrm{OMIM}] \mathrm{BF}_{4}$ coating could be due to the concentration of the IL fluid phase at the surface layer which supports the applied load, and induces a change from brittle to more ductile deformation mechanisms.

\subsection{Films}

$\mathrm{EP}$ and $\mathrm{EP}+9 \%[\mathrm{OMIM}] \mathrm{BF}_{4}$ coatings were deposited on polystyrene (PS) substrate, using the same spin coating technique described for EP substrate, but in this case, the surface films were removed after curing. Thickness of EP and EP+9\%[OMIM $] \mathrm{BF}_{4}$ films, measured with a micrometer, are $0.041 \pm 0.005$ and $0.055 \pm 0.007 \mathrm{~mm}$, respectively. Figures 5 show that both films present a similar visual transparency.

The EP and $\mathrm{EP}+9 \%[\mathrm{OMIM}] \mathrm{BF}_{4}$ films were then characterized by dynamic-mechanical analysis measured under tensile configuration (Table 4; Figure 6) in order to establish the influence of the ionic liquid additive.

The results show that the addition of IL produces the reduction of the glass transition temperature of the film, thus confirming the plasticizing effect of the ionic liquid.

The strong decrease in the storage modulus (Figure 6a) confirms the increased ductility effect of the ionic liquid additive in the epoxy resin film. The similar maximum values and curve width of the dissipation factor $(\tan \delta$ ) (Figure $6 \mathrm{~b}$ ) for both films are in agreement with a uniform distribution of the IL in the epoxy matrix within the film.

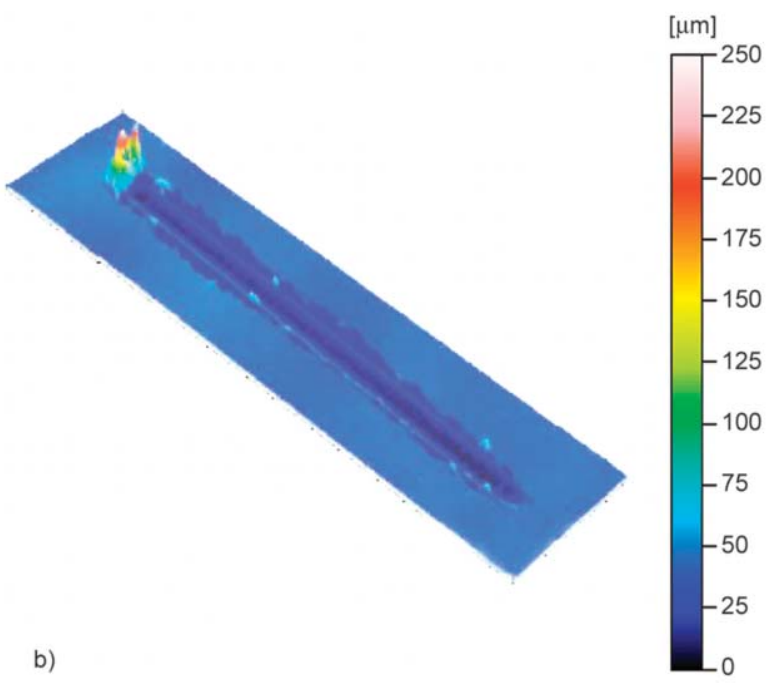

Figure 4. Surface topography of the abrasion scars on: a) EP; b) EP+9\%[OMIM]BF 4 . 


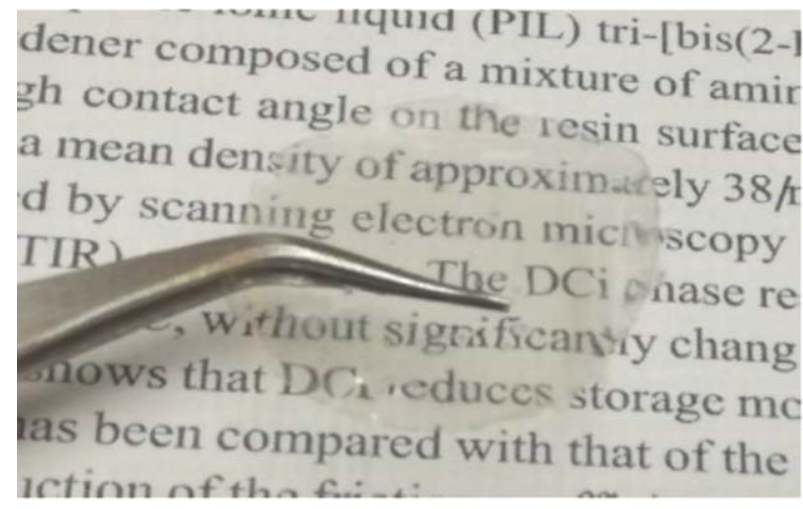

a)

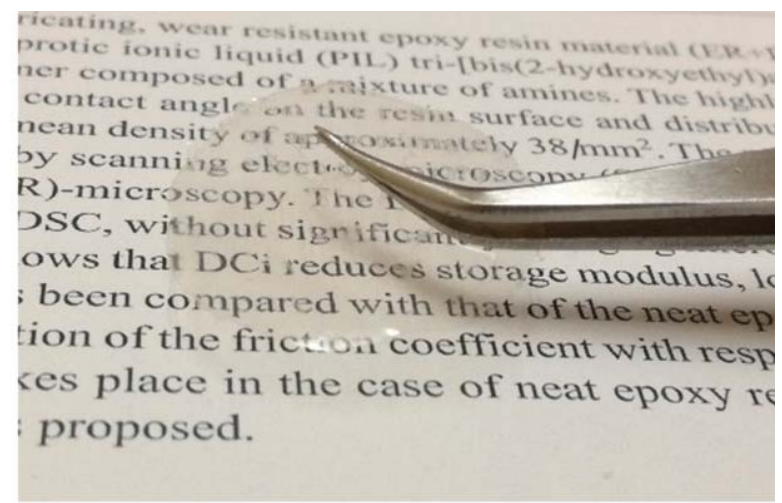

b)

Figure 5. Photographs of the films showing a paragraph of the text of reference [29]: a) EP; b) EP+9\%[OMIM]BF .

Table 4. Dynamic-mechanical properties of $\mathrm{EP}$ and $\mathrm{EP}+9 \%[\mathrm{OMIM}] \mathrm{BF}_{4}$ films.

\begin{tabular}{|c|c|c|c|c|c|c|}
\hline \multirow{2}{*}{ Film } & \multicolumn{2}{|c|}{$\begin{array}{l}\text { Storage modulus } \\
\text { (onset) }\end{array}$} & \multicolumn{2}{|c|}{$\begin{array}{l}\text { Loss modulus } \\
\text { (max.) }\end{array}$} & \multicolumn{2}{|c|}{$\begin{array}{c}\tan \delta \\
(\max .)\end{array}$} \\
\hline & $\begin{array}{c}T \\
{\left[{ }^{\circ} \mathbf{C}\right]}\end{array}$ & $\begin{array}{c}E^{\prime} \\
{[\mathrm{MPa}]}\end{array}$ & $\begin{array}{c}T \\
{\left[{ }^{\circ} \mathbf{C}\right]}\end{array}$ & $\begin{array}{c}E^{\prime \prime} \\
{[\mathrm{MPa}]}\end{array}$ & $\begin{array}{c}T \\
{\left[{ }^{\circ} \mathbf{C}\right]}\end{array}$ & $\tan \delta$ \\
\hline EP & $81.26 \pm 1.54$ & $1056.00 \pm 94.00$ & $83.48 \pm 2.43$ & $277.76 \pm 6.95$ & $97.08 \pm 2.96$ & $1.00 \pm 0.05$ \\
\hline $\mathrm{EP}+9 \%[\mathrm{OMIM}] \mathrm{BF}_{4}$ & $74.08 \pm 0.42$ & $392.61 \pm 40.19$ & $74.94 \pm 0.16$ & $112.73 \pm 10.68$ & $87.89 \pm 0.36$ & $0.97 \pm 0.02$ \\
\hline
\end{tabular}
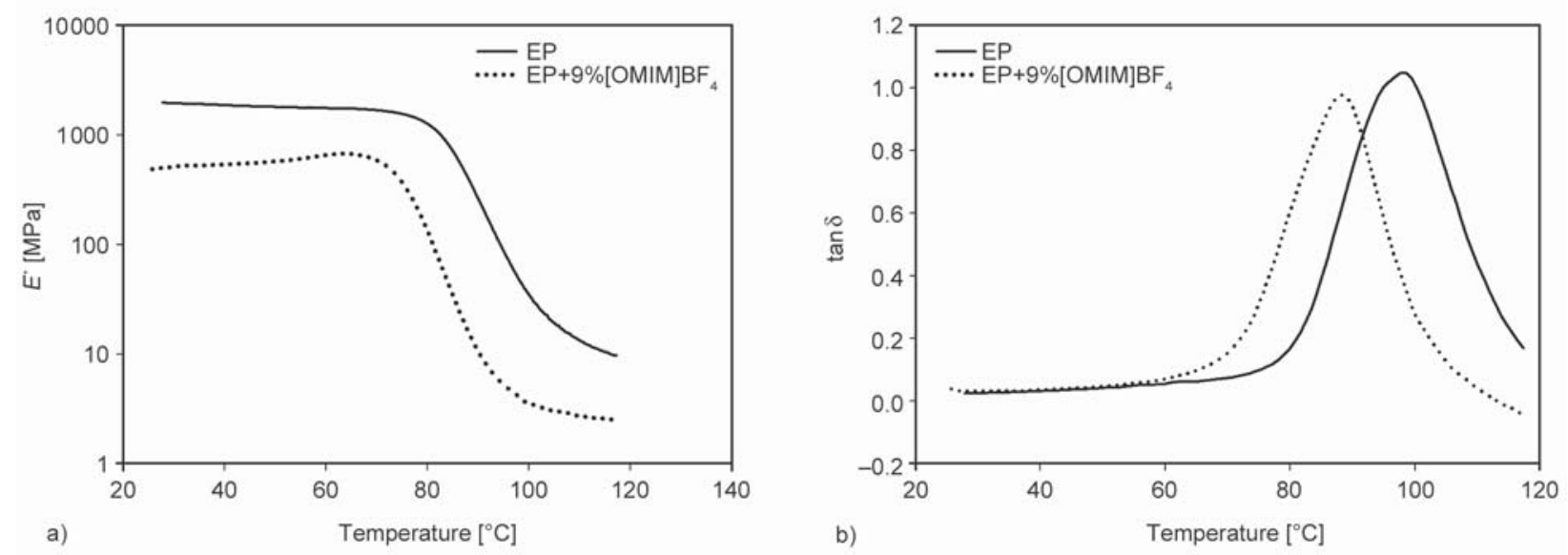

Figure 6. Dynamic-mechanical properties of films under tensile configuration: a) storage modulus; b) $\tan \delta$.

\section{Conclusions}

A spin coating method has been developed to obtain new epoxy resin coatings modified by the addition of ionic liquid. The ionic liquid reduces the thickness and surface roughness of the coating and presents a uniform distribution within the surface layer. The abrasion resistance of the resin coating is increased by the ionic liquid, which induces plastic deformation without material loss after 15 scratches, with lower penetration depth, lower residual depth and higher viscoelastic recovery.

Spin coating has been used to obtain the same materials studied as coatings in the form of films with similar visual transparency. Dynamic mechanical analysis of the films has shown that the ionic liquid reduces the glass transition temperature, thus enhancing chain mobility, while reducing the storage modulus. These results confirm the increased ductility of the epoxy resin. This ductility increase, the plasticizing effect and the lubricating ability of the ionic liquid could explain the different deformation modes under abrasion found for neat epoxy and ionic-liquid modified coatings.

The procedures described here could be used on other substrates for surface protection and tribological applications. 


\section{Acknowledgements}

The authors wish to thank the financial support of the Ministerio de Economía y Competitividad (MINECO, Spain) and the EU FEDER (MAT2017-85130-P), and the Fundación Séneca, Agencia de Ciencia y Tecnología de la Región de Murcia for a 'Ayuda a las Unidades y Grupos de Excelencia Científica de la Región de Murcia' (Grant 19877/GERM/15). M.D. Avilés is grateful to the MINECO (Spain) for a research grant (BES-2015-074836).

\section{References}

[1] Nguyen T. K. L., Livi S., Soares B. G., Pruvost S., Duchet-Rumeau J., Gerard J-F.: Ionic liquids: A new route for the design of epoxy networks. ACS Sustainable Chemistry and Engineering, 4, 481-490 (2016). https://doi.org/10.1021/acssuschemeng.5b00953

[2] Vashchuk A., Fainleib A. M., Starostenko O., Grande D.: Application of ionic liquids in thermosetting polymers: Epoxy and cyanate ester resins. Express Polymer Letters, 12, 898-917 (2018).

https://doi.org/10.3144/expresspolymlett.2018.77

[3] Nguyen T. K. L., Livi S., Soares B. G., Benes H., Gerard J. F., Duchet-Rumeau J.: Toughening of epoxy/ionic liquid networks with thermoplastics based on poly $(2,6-$ dimethyl-1,4-phenylene ether) (PPE). ACS Sustainable Chemistry and Engineering, 5, 1153-1164 (2016). https://doi.org/10.1021/acssuschemeng.6b02479

[4] Mąka H., Spychaj T., Zenker M.: High performance epoxy composites cured with ionic liquids. Journal of Industrial Engineering and Chemistry, 31, 192-198 (2015). https://doi.org/10.1016/j.jiec.2015.06.023

[5] Nguyen T. K. L., Obadia M. M., Serghei A., Livi S., Duchet-Rumeau J., Drockemuller E.: 1,2,3-triazoliumbased epoxy-amine networks: Ion-conducting-polymer electrolytes. Macromolecular Rapid Communication, 37, 1168-1174 (2016).

https://doi.org/10.1002/marc.201600018

[6] Soares B. G.: Ionic liquid: A smart approach for developing conducting polymer composites: A review. Journal of Molecular Liquids, 262, 8-18 (2018). https://doi.org/10.1016/j.molliq.2018.04.049

[7] Maksym P., Tarnacka M., Dzienia A., Matuszek K., Chrobok A., Kaminski K., Paluch M.: Enhanced polymerization rate and conductivity of ionic liquid-based epoxy resin. Macromolecules, 50, 3262-3272 (2017). https://doi.org/10.1021/acs.macromol.6b02749

[8] Nguyen T. K. L., Livi S., Soares B. G., Barra G. M. O., Gerard J-F.: Duchet-Rumeau J.: Development of sustainable thermosets from cardanol-based epoxy prepolymer and ionic liquids. ACS Sustainable Chemistry and Engineering, 5, 8429-8438 (2017).

https://doi.org/10.1021/acssuschemeng.7b02292

[9] Kumar V., Sinha S. K., Agarwal A. K.: Tribological studies of epoxy composites with solid and liquid fillers. Tribology International, 105, 27-36 (2017). https://doi.org/10.1016/j.triboint.2016.09.010
[10] Zhao F., Zhang L., Li G., Guo Y., Qi H., Zhang G.: Significatively enhancing tribological performance of epoxy by filling with ionic liquid functionalized graphene oxide. Carbon, 136, 309-319 (2018).

https://doi.org/10.1016/j.carbon.2018.05.002

[11] Alhumade H., Yu A., Elkamel A., Simon L., Abdala A.: Enhanced protective properties and UV stability of epoxy/graphene nanocomposite coating on stainless steel. Express Polymer Letters, 10, 1034-1046 (2016). https://doi.org/10.3144/expresspolymlett.2016.96

[12] Bobby S., Samad M. A.: Enhancement of tribological performance of epoxy bulk composites and composite coatings using micro/nano fillers: A review. Polymers for Advanced Technologies, 28, 633-644 (2017). https://doi.org/10.1002/pat.3961

[13] Serra A., Ramis X., Fernández-Francos X.: Epoxy solgel hybrid thermosets. Coatings, 6, 8/1-8/19 (2016). https://doi.org/10.3390/coatings6010008

[14] Ghaleb Z. A., Mariatti M., Ariff Z. M.: Graphene nanoparticle dispersion in epoxy thin film composites for electronic applications: Effect on tensile, electrical and thermal properties. Journal of Materials Science: Materials in Electronics, 28, 808-817 (2017). https://doi.org/10.1007/s10854-016-5594-y

[15] Saurín N., Sanes J., Carrión F. J., Bermúdez M. D.: Self-healing of abrasion damage on epoxy resin controlled by ionic liquid. RSC Advances, 6, 37258-37264 (2016). https://doi.org/10.1039/c6ra05503f

[16] Saurín N., Sanes J., Bermúdez M. D.: Effect of graphene and ionic liquid additives on the tribological performance of epoxy resin. Tribology Letters, 56, 133-142 (2014). https://doi.org/10.1007/s11249-014-0392-2

[17] Sanes J., Saurín N., Carrión F. J., Ojados G., Bermúdez M. D.: Synergy between single-walled carbon nanotubes and ionic liquid in epoxy resin nanocomposites. Composites Part B: Engineering, 105, 149-159 (2016). https://doi.org/10.1016/j.compositesb.2016.08.044

[18] Saurín N., Sanes J., Bermúdez M. D.: Self-healing of abrasion damage in epoxy resin-ionic liquid nanocomposites. Tribology Letters, 58, 4/1-4/9 (2015). https://doi.org/10.1007/s11249-015-0490-9

[19] Sanes J., Carrión F. J., Bermúdez M. D.: Effect of the addition of room temperature ionic liquid and $\mathrm{ZnO}$ nanoparticles on the wear and scratch resistance of epoxy resin. Wear, 268, 1295-1302 (2010). https://doi.org/10.1016/j.wear.2010.01.024

[20] Sanes J., Carrión-Vilches F. J., Bermúdez M. D.: New epoxy-ionic liquid dispersions. Room temperature ionic liquid as lubricant of epoxy resin-stainless steel contacts. e-Polymers, no.005 (2007). https://doi.org/10.1515/epoly.2007.7.1.48

[21] Hameed N., Salim N. V., Walsh T. R., Wiggins J. S., Ajayan P. M., Fox B. L.: Ductile thermoset polymers via controlling network flexibility. Chemical Communications, 51, 9903-9906 (2015). https://oi.org/10.1039/C4CC10192H 
[22] Clausi M., Santonicola M., Laurenzi S.: Fabrication of carbon-based nanocomposite films by spin-coating process: An experimental and modeling study of the film thickness. Composites Part A, 88, 86-97 (2016). https://doi.org/10.1016/j.compositesa.2016.05.026

[23] Uddin M. A., Chan H. P., Chow C. K.: Thermal and chemical stability of a spin-coated epoxy adhesive for the fabrication of a polymer optical waveguide. Chemistry of Materials, 16, 4806-4811 (2004). https://doi.org/10.1021/cm0496927

[24] Barbakadze K., Brostow W., Datashvili T., Hnatchuk N., Lekishvili N.: Antibiocorrosive epoxy-based coatings with low friction and high scratch resistance. Wear, 394-395, 228-235 (2018).

https://doi.org/10.1016/j.wear.2017.08.006

[25] Brostow W., Hagg Lobland H. E.: Materials: Introduction and applications. Wiley, Hoboken (2017).
[26] Avilés M. D., Saurín N., Jiménez A. E., Bermúdez M. D., Carrión F. J., Sanes J.: Tribological characterization of epoxy coatings modified with ionic liquids and graphene. in ' $45^{\text {th }}$ Leeds-Lyon Symposium on Tribology. Smart Tribology Systems. Leeds, UK’ 11.4 (2018).

[27] Brostow W., Damarla G., Howe J., Pietkiewicz D.: Determination of wear of surfaces by scratch testing. e-Polymers, no.025 (2004).

https://doi.org/10.1515/epoly.2004.4.1.255

[28] Brostow W., Hagg Lobland H. E., Khoja S.: Brittleness and toughness of polymers and other materials. Materials Letters, 159, 478-480 (2015). https://doi.org/10.1016/j.matlet.2015.07.047

[29] Avilés M. D., Saurín N., Espinosa T., Sanes J., AriasPardilla J., Carrión F. J., Bermúdez M. D.: Self-lubricating, wear resistant protic ionic liquid-epoxy resin. Express Polymer Letters, 11, 219-229 (2017). https://doi.org/10.3144/expresspolymlett.2017.23 